\title{
DOS NOTAS (I. GLOSAS SOBRE LO DIACRÓNICO. II. MENÉNDEZ PIDAL Y AMÉRICO CASTRO EN EL CONTEX- TO DE LA HISTORIOGRAFÍA)
}

Francisco Abad

UNED. Madrid

\section{RESUMEN}

La primera de estas notas ultima el comentario a la obra de Eugenio Coseriu Sincronía, diacronía e historia que comenzamos en un número anterior; glosamos y desarrollamos brevemente algunas de las ideas mantenidas por el autor. La segunda Nota se ocupa de la historiografia del siglo XX, y en ella se detiene en don Ramón Menéndez Pidal y en Américo Castro.

\section{GLOSAS SOBRE LO DIACRÓNICO ${ }^{1}$}

\section{Lo idiomático frente a lo filológico}

Cuando en un idioma dado se pasa «del fonema $x$ al fonema y» no estamos sólo ante un hecho «de fisiología de la articulación» - enseña nuestro autor - , sino que se plantea un problema histórico ${ }^{2}$. Se trata entonces de una condición físiológica necesaria (diríamos) a la que no podemos reducir el hecho del cambio de esa $x$ en $y$; la lengua

${ }^{1}$ Completamos el comentario que iniciamos en su día (EPOS, XV, 1999) - con propósito de utilidad pedagógica - , al libro de Eugenio Coseriu, Sincronía, diacronía e historia, citado según su tercera ed., Madrid, Gredos, 1978.

${ }^{2}$ Sincronia..., pp. 143-144. 
tiene por supuesto un componente natural fisiológico, pero tal componente no constituye lo idiomático en sí: lo idiomático es formal-intransitivo y funcional (además de histórico), y por eso es cultural y no natural. «El idioma es un saber interindividual, y no un aparato fonador ${ }^{3}$, es decir, una construcción histórico-cultural y no sólo una manifestación fisiológica.

Coseriu ejemplifica en un momento con la diacronía del castellano los hechos de que en el lenguaje se tienen las finalidades de «hablar como el otro» y de «hablar para que el otro entienda ${ }^{4}$, lo que hace que los resultados idiomáticos no deriven nada más que de "razones sistemáticas» inmanentes, sino de hechos de historia general y social. La nivelación lingüística se produce como consecuencia del contacto de poblaciones: no se trata nada más - decimos - que de motivos internos al sistema (por ej. para alcanzar una mayor diferenciación y margen de seguridad fónicos), sino de reelaboraciones diacrónicas que precipitan de un hecho histórico-social o cultural. En cualquier caso ocurre por tanto que «las explicaciones funcionales de los cambios lingüísticos no excluyen, sino que implican las explicaciones culturales" ${ }^{5}$.

Dice nuestro autor en un momento de su discurrir que la expresividad de un texto se mide en referencia a una finalidad expresiva concreta ${ }^{6}$. Estamos ante un aspecto del llamado tradicionalmente «decoro», o sea, ante la 'adecuación del lenguaje de una obra literaria al género, al tema y a la condición de los personajes', tal como define el $D R A E$; esta cuestión del decoro se halla presente - según bien se sabe, y lo recordamos ahora meramente como ilustración - en el Arte nuevo de Lope de Vega, en el que el dramaturgo manifiesta:

Si hablare el rey, imite cuanto pueda

la gravedad real; si el viejo hablare procure una modestia sentenciosa.

Describa los amantes con afectos que muevan con extremo a quien escucha. $[\ldots]$

El lacayo no trate cosas altas

ni diga los conceptos que hemos visto en algunas comedias extranjeras.

Tenemos así en este caso que el hablar de cada personaje ha de guardar el decoro de adecuarse a su cualidad social, a la edad que tenga, a la situación en la que se manifiesta, etc.

Lope trata de varias identidades sociales: el rey, el viejo, los amantes, el lacayo; el rey ha de manifestarse con gravedad, el viejo con concepto o sentencia, dirigiéndose

${ }^{3}$ Ibid., p. 144.

${ }^{4}$ Ibid., pp. 152-153.

${ }^{5}$ Ibid., p. 177.

"Y ejemplifica: «La Crítica de la razón pura y la Fenomenología del espíritu son también obras literariamente logradas porque su forma de expresión corresponde, aun en sentido «subjetivo», a su finalidad expresiva, y no lo serían si presentaran por ej. el estilo de una novela policíaca. En cambio una $[\mathrm{H}]$ istoria de la filosofía como la de B. Russell molesta - entre otras cosas más graves - también por su estilo conversador y periodístico» (Ibid., p. 170 n.). 
pues al intelecto, mientras los amantes —así lo glosó Juan Manuel Rozas- «[dan] la connotación pasional y subjetiva, con brillo poético y lenguaje imaginativo y metafórico». Con los lacayos ocurre que a veces se expresan de manera culta, a veces - según han observado los estudiosos - haciendo uso de la convención o recurso de «escuché al cura en la iglesia que», etc.

\section{Ciencia cultural y ciencia natural}

Inserto en la tradición de pensamiento germánico de fines del siglo XIX y comienzos del XX, Coseriu opera siempre de manera implícita con el deslinde y la caracterización diferenciada de las ciencias de lo natural y las ciencias histórico-culturales, y en este sentido escribe:

Pero una explicación universal no es de por sí una explicación histórica. Para explicar por qué el futuro latino se sustituyó por formas modales en una determinada época, no basta con comprobar que se trata de algo que "suele ocurrir» y con señalar la razón universal del fenómeno. Hay que explicar también por qué esa razón universal (y permanente) resultó operante precisamente en la época del llamado latín vulgar: es decir que la necesidad expresiva universal debe justificarse como necesidad histórica? ${ }^{7}$.

Apelar a las explicaciones universales y genéricas no es hacer historia, sino ilustrar meramente los hechos humanos - cuando se trata de ellos - en su consistencia más abstracta e incolora; la historia de la cultura no es un devenir de universales genéricos, sino de realizaciones y logros valiosos cada uno por sí mismo y no intercambiables. Kant no hace innecesario a Descartes, ni Luis Cernuda a Quevedo.

Nos encontramos pues ante la especificidad de lo linguístico y del arte verbal (abordado por las ciencias del espíritu) frente al mundo de lo natural, que abordan las ciencias de la Naturaleza. El arte por ej. - -en este caso el arte literario- es específico, individual, no se repite más que una vez: una sola vez se han escrito el Quijote o Así que pasen cinco años de García Lorca. Las composiciones literarias han de quedar avaloradas por sí mismas, cada una en su individualidad irrepetida: constituyen valores únicos y perdurables que siempre han de considerarse.

Según proclamaba Dilthey las ciencias del espíritu han de aprehender lo individual de la realidad histórico-social; más enérgicamente manifestaba asimismo que en tales ciencias se deberá «descartar de un modo definitivo la subordinación de sus principios o de sus métodos a los de las ciencias de la naturaleza» ${ }^{8}$.

Tenemos que por ej. un televisor mejor supera a otro peor, y así al peor lo tiramos a la basura; una lavadora más moderna supera a otra más antigua, etc. Es lo que ocurre en el mundo de lo natural: el progreso hace obsoletos a los objetos.

En el mundo del espíritu y de la cultura ocurre lo contrario: las obras posteriores no superan a las anteriores, y porque exista Goya no quemamos los cuadros de Velázquez,

\footnotetext{
${ }^{7}$ Ibid, p. 173.

${ }^{8}$ Wilhelm Dilthey, Introducción a las ciencias del espiritu, trad. esp., Madrid, Alianza, 1980, pp. 71 y 178 .
} 
y porque escriba Valle-Inclán no destruimos por eso las obras del príncipe (que se llamaba a sí mismo «infante») don Juan Manuel.

En lingüística hay un autor que ha insistido mucho en la especificidad cultural y espiritual del lenguaje, y es justamente nuestro autor, aunque antes de él lo hiciese asimismo Karl Vossler, etc..

Las cosas no ocurren universalmente en el mundo de la cultura aunque sí en el de la Naturaleza: en el de la cultura todo es individual y único cada vez. Puede decir así el lingüista rumano:

Los cambios lingüísticos en cuanto hechos históricos particulares no pueden explicarse sólo universal y genéricamente, sino que deben ser explicados en su particularidad. Dar sólo una explicación genérica de un cambio históricamente determinado es como decir que una casa se ha incendiado 'porque el fuego quema la madera', lo cual es cierto desde el punto de vista genérico (o sea, desde el punto de vista que es propio de las ciencias naturales), pero no nos dice nada acerca de la causa histórica (particular) del incendio ${ }^{10}$.

Lo histórico es particular y específico, y sólo se aprehende si lo consideramos de esta manera: un individuo cualquiera no muere porque el ser humano es mortal, sino por una dolencia concreta hepática, o pulmonar, etc.; una nación no entra en guerra porque sea un principio general la defensa de su consistencia territorial, sino porque esa integridad del territorio ha quedado rota y usurpada en alguna de sus partes en un momento histórico dado y en circunstancias particulares asimismo dadas; etc. A este respecto Coseriu recuerda cómo Menéndez Pidal apelaba a precisas causas históricas determinantes en cuanto motivo de los cambios lingüísticos "i ; don Ramón en efecto - y como buen historiador - era muy analítico, no mezclaba consistencias o identidades diferenciadas, y así por ej. distinguió siempre los «siglos de oro» de nuestra cultura porque para él una cosa era el XVI y otra el XVII: 1610 (fecha del «segundo» Góngora) daba lugar en su percepción a una nueva época en la historia idiomática castellana ${ }^{12}$.

Precisa incluso más Coseriu en cuanto a la delimitación de lo natural y lo cultural, y hace por eso un deslinde asimismo terminológico: «los objetos culturales - escribe-

${ }^{9}$ El olvido hacia Vossler se muestra en un hecho que hemos podido comprobar no hace mucho: el «Proyecto docente» de un opositor u opositora dedicaba dos líneas y poquísimas referencias a tal autor, mientras algunos profesores jóvenes cuyas aportaciones no resultan imprescindibles aparecian citados una y otra vez. Hoy día se asiste en bastantes ocasiones a la creencia -que no puede justificarse racionalmente - de que lo último publicado es lo mejor, y se ignora así a los grandes autores, o incluso se les sigue (o se les copia) sin mencionarlos; podríamos ejemplificarlo en concreto.

${ }^{10}$ Sincronia..., pp. 184-185.

"Ibid., p. 186 n.

${ }^{12}$ Cfr. Ramón Menéndez Pidal, La lengua castellana en el siglo XVII, Madrid, Espasa Calpe, 1991, pp. $63 \mathrm{y}$ ss.

Rickert había proclamado a su vez que las ciencias históricas o culturales «no se preocupan en absoluto de formar conceptos universales», y que «la significación cultural de un objeto [...] no está en lo que ese objeto tiene de común con otras realidades, sino justamente en lo que lo distingue de las demás». Muy expresivamente afirmaba por igual: «La realidad se hace naturaleza cuando la consideramos con referencia a lo universal; se hace historia cuando la consideramos con referencia a lo particular e individual» (H. Rickert, Ciencia cultural y ciencia natural, trad. cast., Madrid, Espasa-Calpe, 19654, pp. 90,92 y 124 para lo citado). 
tienen desarrollo histórico, y no "evolución» como los objetos naturales» ${ }^{13}$; en este caso desarrollo se refiere a lo que ocurre o acontece, a lo que sucede y tiene lugar en el mundo de la historia y la cultura.

\section{Finalidad vs. causalidad}

Ya decimos cómo nuestro autor inserta su discurrir en la tradición de la filosofía alemana que distinguió las ciencias del espíritu de las ciencias naturales; en tal entendido proclama:

En [los objetos culturales...] lo que efectivamente se da y se comprueba son la libertad y la intencionalidad, la invención, la creación y la adopción libres, motivadas sólo finalísticamente. En los fenómenos de la naturaleza corresponde sin duda buscar una necesidad exterior o causalidad; en los fenómenos culturales en cambio lo que corresponde buscar es una necesidad interior o finalidad. Por lo tanto una concepción realmente positiva (y no «positivista») acerca del lenguaje debe advertir y recordar constantemente que el lenguaje pertenece al dominio de la libertad y de la finalidad, y que por consiguiente los hechos lingüísticos no pueden interpretarse y explicarse en términos causales ${ }^{14}$.

Lo espiritual en efecto no es necesario ineluctablemente, sino que es libre: no estamos ante la circunstancia de un motivo que determina algo según ocurre en lo natural, sino en todo caso ante una causa final, ante lo que en términos genéricos se ha definido como un objetivo o el 'interés por el que se actúa'; el interés del que habla o escribe es desde luego su designio comunicativo y expresivo. En la Naturaleza hablamos de causas en general sin embargo en el sentido de 'producción de algo de acuerdo con una cierta norma' o de 'el acontecer algo según una cierta ley que rige para todos los acontecimientos de la misma especie', según parafrasea el término causa José Ferrater Mora en su Diccionario de filosofía. Los objetos culturales llevan en sí una motivación finalística, señala el lingüista rumano, y la filosofía tradicional enseñaba que «la causa final es la primera de las causas, por cuanto bajo su influencia la causa eficiente se pone a obrar, a dar a la causa material tal causa formal» ${ }^{15}$.

La causalidad necesaria y «ciega» - digámoslo así- ocurre en los objetos físicos, y por eso en los libros más elementales de la enseñanza media puede exponerse por ej.: «La observación consiste en examinar los fenómenos tal como se producen en la Naturaleza. [...] La experimentación consiste en repetir los fenómenos en laboratorios [...] realizándolos en circunstancias muy variadas, con el fin de deducir con toda precisión las leyes y las fórmulas matemáticas que relacionan las causas y los efectos» ${ }^{16}$.

Tratamos en definitiva con la ciencia natural de establecer las leyes que analizan las relaciones entre causas y efectos en múltiples circunstancias, y de esta manera hablamos - se trata del mero ejemplo de una ley - de que «en el movimiento variado se llama ve-

\footnotetext{
${ }^{13}$ Sincronia..., p. $181 \mathrm{n}$.

14 Ibid., pp. 193-194.

${ }^{15}$ Copiamos del Manual de filosofia tomista de E. Collin, trad. cast., Barcelona, Luis Gili, 1942, 1, p. 168.

${ }^{16}$ Este pasaje aparece en la Física y Química de C. Marcos y J. Martínez, Madrid, S. M., 1964, p. 2.
} 
locidad media $\left(\mathrm{v}_{\mathrm{m}}\right)$ en un intervalo de tiempo dado al cociente del trayecto recorrido por el tiempo empleado en ${ }^{3}$ el mismo» ${ }^{17}$, etc.

Otro es el mundo del espíritu, que se mueve finalista y por tanto libremente; en los logros de ese espíritu - entre ellos los lingüísticos - la única causalidad reside en la libertad y en la finalidad (en este caso expresiva) que se pretende. Incluso para la más limitada competencia idiomática resulta posible hacer uso de un registro respetuoso y de otro familiar de acuerdo con finalidades actuativas, etc. En filosofía se dice en general - tal como parafrasea asimismo Ferrater- que «el fin es propiamente la causa de la acción de la causa eficiente».

De acuerdo con lo anterior ocurre que «la lingüística debe renunciar al propósito irracional de establecer leyes causales en el dominio de la libertad. Con ello no renunciara ser «exacta», sino que al contrario adquirirá su plena exactitud como ciencia del hombre» ${ }^{18}$. Las «leyes» idiomáticas que podamos establecer no son causales y necesarias, sino que proponemos calificarlas de situacionales; se tratará de explicaciones que surgen del análisis de la situación histórico - lingüística dada: por ej. el análisis diastrático nos lleva a explicaciones socio-culturales de la dialectalización vertical del hablar, etc. ${ }^{19}$.

Acaso podría pensarse que justamente la encuesta sociolinguística lo que nos enseña es la determinación socio-cultural del hablar, pero si bien esto es así en parte, en parte ocurre que cada hablante posee el saber idiomático y la libertad para modelar aspectos de su discurso según la finalidad y según esa libertad: el menos culto de todos los hablantes sabe de manera implícita manejar el usted / tú, el diminutivo, etc. La ultracorrección supone un error, pero asimismo una libertad expresiva en cuanto puede derivar del designio de la expresión mejor.

No resulta contradictorio - por tanto- decir que el cambio idiomático posee causas, proclama Coseriu: no las tiene en sentido naturalista y ajenas a la libertad, pero sí tiene causas eficiente (la innovación lingüística se hace por alguien), formal (con la idea de lo que se hace), final (se hace para algo), etc. ${ }^{20}$. Reformulando en algo a nuestro autor podríamos exponer que el cambio lingüístico posee en tanto causa formal extrínseca lo que lo especifica desde fuera, y en ello entra lo que Menéndez Pidal denominaba gusto idiomático por la diptongación, o por el cultismo, ... El cambio además vemos que se hace para algo (causa final); en filosofía se enseña genéricamente - así lo decía el manual que nosotros debíamos aprender en primer curso de la licenciatura - que «el fin en tanto que causa es el principal determinante de una pretensión del agente» ${ }^{21}$.

Haciendo énfasis en la libertad linguística que se traduce en un logro de finalidad expresiva, el autor rumano formula en definitiva que «el cambio lingüístico tiene efectivamente una causa eficiente que es la libertad lingüística, y una razón universal que es la finalidad expresiva (y comunicativa) de los hablantes ${ }^{22}$. Ciertamente el fin del hablante es comunicarse y expresarse, y de acuerdo con tal teleología moviliza sus saberes idiomáticos.

${ }^{17}$ Ibid., p. 10.

${ }^{18}$ Sincronia..., pp. 236-237.

${ }^{19}$ Aunque los estudiosos le hayan señalado limitaciones empíricas y de método, seguramente el primer trabajo orgánico acerca de la diastratía de un habla hispánica fue el llevado a cabo por Manuel Alvar en su libro Niveles socio-culturales en el habla de Las Palmas de Gran Canaria, Las Palmas, Cabildo Insular, 1972.

${ }^{20}$ Sincronía..., pp. 200-201.

${ }^{21}$ Antonio Millán Puelles, Fundamentos de filosofía, Madrid, Rialp, 1962 ${ }^{3}$, p. 525.

22 Sincronía..., p. 205. 
El hablar según la libertad parte desde luego de la tradición pero la renueva, y esa tensión entre tradición e innovación es la que va configurando un idioma histórico concreto. Fue Menéndez Pidal quien insistió en uno de estos aspectos, en el de lo mucho que tiene toda lengua de tradicionalidad, y la mayor consistencia de lo tradicional la señaló justamente en el lenguaje.

Don Ramón estableció efectivamente grados en la tradición, es decir, grados de consistencia tradicional en diversas actividades colectivas: lo más tradicional de todo le parecía el lenguaje - siempre en boca de todos y siempre empleado ininterrumpidamente,$- y$ de ahí que el individuo pueda intervenir difícilmente en cambiarlo; segundo grado de tradicionalidad (o sea, menor tradicionalidad) - enseña - presenta el romance:

El romance, aunque fijado por el verso, vive en variantes, porque cada uno que lo canta lo considera como cosa propia [...]. Y sin embargo aunque la canción vive continuamente variada, queda esencialmente invariable. El romance goza de grande aunque relativa estabilidad, ya que las continuas iniciativas individuales son efímeras en la inmensa mayoría de los casos, pues son rechazadas por los oyentes que mantienen su adhesión a la forma versificada consabida de todos [...]. Sólo cuando alguna innovación de recitador logra agradar a unos y otros oyentes, llega a incorporarse al texto del romance ${ }^{23}$.

El romance posee menor grado de tradicionalidad que el lenguaje, en su vida intervienen menos gentes, se halla en boca de menos - la lengua la hablan todos-, y así una innovación feliz puede incorporarse al texto romanceril y emigrar a varios lugares y difundirse.

Por fin el que don Ramón llama tercer grado de tradicionalidad o tradicionalidad menor es el del cantar de gesta: ahora «al ser menor el número de cantores y de oyentes que intervienen en la trasmisión, las variantes orales pueden introducirse más libremente», y de esta manera -en general - el juglar puede rehacer y refundir los relatos épicos ${ }^{24}$.

La densidad o consistencia de la tradicionalidad en ellos hacen más inmutable el idioma, menos el romance, y menos el cantar de gesta: cuando hay menor tradicionalidad, resulta más fácil que las innovaciones se abran paso.

\section{Sobre lengua y cultura}

Nuestro autor no se satisface con subrayar la tesis idealista de que la lengua es espejo de la cultura, sino que (con buen sentido) proclama que la lengua forma parte de la cultura en cuanto un hecho de ella: la lengua - mantiene de esta manera - «es ella misma una zona esencial de la cultura, con tradición, estructura y normas propias ${ }^{25}$. Resulta así que la historia de la lengua, la diastratía del hablar, los logros elocutivos de la literatura, etc., constituyen otros tantos componentes de la historia cultural de un colectivo humano: las letras bellas lo constituyen, sí, pero asimismo la lengua, las ciencias, ... Esta proclama coseriana a favor del idioma considerado en sí mismo como parte de los hechos de cultura, resulta particularmente de relieve.

${ }^{23}$ Ramón Menéndez Pidal, Poesia juglaresca y origenes de las literaturas románicas, Madrid, IEP, 1957, pp. 367-368.

${ }^{24}$ Ibid., p. 369.

${ }^{25}$ Sincronía..., p. 218. 
Hecho particular también de cultura es el de la propagación según gradaciones cronologicas y geográficas de las innovaciones lingüísticas hasta dar en otros tantos cambios; en cualquier caso se trata de que «entre el punto de partida (innovación) y el de llegada (mutación) está el cambiar mismo como «difusión», es decir, como adopción interindividual de la innovación, proceso histórico sumamente complejo [...] en cuyo estudio se ha destacado sobre todo la escuela lingüística española ${ }^{26}$. Efectivamente fue Menéndez Pidal el gran maestro que iluminó estos procesos de difusión de las innovaciones en su obra maestra Origenes del español, pero asimismo en la historia romanceril ${ }^{27}$; por igual datos para el análisis de la difusión de las innovaciones se encuentran en los dos volúmenes de la obra inacabada de Amado Alonso que se editó con el título - verosímilmente debido a Rafael Lapesa-De la pronunciación medieval a la moderna en español.

$\mathrm{Al}$ recordar a la «escuela española» pidalina, venía Coseriu a notar de hecho la idea mantenida por tal escuela del lenguaje en tanto un producto cultural. Don Ramón y sus discípulos fueron filólogos más que lingüistas, o mejor dicho, fueron filólogos además de lingüistas, y sabido es - se ha dicho alguna vez - que ser filólogo resulta más difícil que ser lingüista, pues han de allegarse más saberes y obliga a ampliar continuamente la información y la formación que se tenga: el filólogo ha de estar formándose continuamente.

La lengua es cultura y vehicula la cultura, ya que no existe discurso alguno sin capacidad referencial, sin un horizonte de alusividad al que remite. «No hay lengua sin significación", nos dicta la evidencia y repite Coseriu ${ }^{28}$.

Justamente el hecho de que los discursos son significativos, de que poseen referencialidad, es lo que invalida en parte la concepción sólo formalista de la literatura. Hay lingüistas que suelen decir que un poema se explica "desde la lengua», pero no es de esta manera nada más; con lo lingüístico podemos empezar a razonar la esteticidad del poema, pero el mismo lleva en sí además una sustancia del contenido y la connota, y lleva esa sustancia porque de la misma es portadora la lengua en que se halla escrito el texto de que se trate.

Las obras de arte verbal existen desde luego «en sí», pero no sólo en sí: no verlo es cerrarse en una actitud cómoda en definitiva, pues evita muchas búsquedas en la investigación.

\section{Descripción e historia lingüísticas}

El sistema lingüístico existe «porque se hace», manifiesta nuestro autor ${ }^{29}$, y en efecto así ocurre: la lengua es una esencial diversificación, y tal diversificación - si se consolida - da lugar a la constitución concreta del sistema idiomático.

Con gran lucidez y en términos más amplios, dice Coseriu que aquello por lo cual la lengua es lengua «no es simplemente su estructura (que es sólo la condición de su funcionamiento), sino la actividad lingüística que la crea y la mantiene como tradición» ${ }^{30}$. El ha-

${ }^{26}$ Ibid., p. 221

${ }^{27}$ Cfr. en este sentido las páginas «Sobre geografía folklórica» de los Estudios sobre el romancero pidalinos: Madrid, Espasa-Calpe, 1973,pp. 217-323.

${ }^{28}$ Sincronia..., p. 265 . Ocurre en concreto - dice - que «con la sustancia del "contenido», la forma lingüística contrae una función de «interdependencia» (relación entre dos constantes), pues no puede darse ni concebirse sin ella».

29 Ibid., p. 271.

30 Ibid. 
blar se va haciendo «lengua» una y otra vez mediante la innovación y el cambio idiomático; la lengua alcanza la fisonomía particular que le van dando su tradicionalidad y sus cambios. Por eso nosotros reformularíamos la conocida idea coseriana de que «la lengua funciona sincrónicamente y se constituye diacrónicamente ${ }^{31}$, diciendo -entiéndanse estas palabras al menos en su espíritu - que la lengua funciona y se constituye sincrónica y diacrónicamente: la fisonomía de un idioma se constituye sincrónicamente, y asimismo cabría decir que funciona diacrónicamente, en cuanto la sustitución de un hecho sistemático por otro, la lenta difusión e implantación del mismo, etc., no dejan de perder de vista lo propiamente interno y estructural. Las dimensiones sincrónica y diacrónica del hablar se nos muestran inescindibles; en cada sincronía la diacronía se halla asimismo actuante, y la diacronía no consiste sino en la historia entrecruzada de las sincronías. Ocurre así - por tal inescindibilidad aludida - que la descripción «debe dar cuenta de las posibilidades abiertas, de todo aquello que es «pauta productiva», esquema aplicable para la realización de lo que no existe aún como norma; y ello no sólo en la morfología, sino también en la sintaxis, en el léxico (derivación y composición de palabras)», etc. ${ }^{32}$.

En la investigación - propone Coseriu en fin - ha de hablarse «de descripción e historia de la lengua. La descripción y la historia de la lengua se sitúan ambas en el nivel histórico del lenguaje y constituyen juntas la lingüística histórica (estudio de las lenguas)» ${ }^{33}$. Como el hablar es siempre tradición, ocurre en efecto que la descripción se sitúa en el nivel histórico del lenguaje, pues una lengua - aun en cualquiera de sus momentos sincrónicos - no es sino un producto tradicional y de la historia idiomática.

Sincronía, diacronía e historia es seguramente la más amplia y densa meditación muy lúcida en varias de sus formulaciones - acerca del problema del cambio lingüístico, que se haya hecho en castellano; a su mejor entendimiento hemos pretendido contribuir ${ }^{34}$.

\section{Menéndez PIDAl y Américo Castro en El CONTEXTo de la historiogRafía}

\section{Consideraciones preliminares}

La historiografía española del siglo XX queda aún por estudiar suficientemente - la historiografía tout court, asimismo la de las ideas linguiísticas y literarias, etc.-, aunque desde luego hay ya algunas monografías.

Por ejemplo y referido a los decenios últimos del Ochocientos se encuentra el inteligente planteamiento de Marta Campomar en torno a un autor que es también del siglo XX: Menéndez Pelayo; ella es en efecto autora del libro La cuestión religiosa en la Restauración. «Historia de los Heterodoxos Españoles» ${ }^{35}$. Sobre «Las ciencias históricas» en la «Edad de Plata» de nuestra cultura ha escrito unas páginas Manuel Fernández Álvarez, si bien demasiado sumarias y que en conjunto no creemos objetivamente satisfactorias;

\footnotetext{
${ }^{31}$ Ibid., p. 272.

${ }^{32}$ Ibid., p. 273.

${ }^{33}$ Ibid., p. 282.

${ }^{34}$ [Vid. ahora C. Company, «La gramaticalización en la historia del español», Medievalia, 35, 2003, pp.

${ }^{35}$ Santander, Sociedad Menéndez Pelayo, 1984, 328 págs.
} 3-61]. 
estas páginas se hallan en un planteamiento global -el de los dos volúmenes de la Historia de España de Menéndez Pidal dedicados a «La Edad de Plata de la cultura Española (1898-1936)» - que tampoco creemos inobjetable: tal Edad de Plata viene ya de antes de 1898, y creemos que supone una simplificación identificarla sólo con más o menos los tiempos del reinado de Alfonso XIII y de la República (¿cómo puede dejarse a Giner, a Galdós, o a la Institución Libre de Enseñanza fuera de nuestra Edad de Plata? ${ }^{36}$.

Asimismo y sobre «Historiografía e ideología en la postguerra española: la ruptura de la tradición liberal» ha escrito su tesis de doctorado Gonzalo Pasamar, texto impregnado de un aliento militante que quizá no resulta necesario, y en el que a veces se hubiera deseado acaso mayor detalle analítico cuando se abordan autores y textos de relieve ${ }^{37}$.

En todo caso ya decimos que quizá falta un texto de conjunto en el que se exponga de manera sintética pero con algún detalle analítico, la historiografía española del siglo $\mathrm{XX}^{38}$; nosotros ahora vamos a apuntar simplemente alguna idea general que pueda resultar útil y algo sobre Menéndez Pidal y Américo Castro.

Cabe decir además que las historiografías particulares se hallan necesitadas por igual de una labor primaria que precipite en las necesarias exposiciones globales; las ideas lingüísticas y las ideas crítico-literarias del Ochocientos y del Novecientos español no se encuentran aún mínimamente sistematizadas, e incluso se diría que existe una voluntad de introducir confusión que haga que no resalten los verdaderos valores, los más altos: por ej. el mismo Menéndez Pidal o Rafael Lapesa son objeto a veces de más faltas de respeto de lo que podría imaginarse, y lo decimos porque hemos sido testigos de ello. Julián Marías también ha llamado la atención sobre esta «envidia retrospectiva» que hace que se induzca a no reconocer a los más relevantes autores, entre ellos justamente a don Ramón Menéndez Pidal:

Irrita a algunos - dice Marías - que autores muertos [...] sigan siendo leídos, admirados, produzcan placer, iluminación, en algunas ocasiones consuelo. Ciertos vivientes tienen la impresión de que esos muertos les «usurpan» lo que creen que les es debido - o lo que es peor: lo que saben que no les es debido- . [... En España...] son objeto de «envidia retrospectiva» unos cuantos autores. Principalmente [...] Menéndez Pidal, Galdós [...]. Los envidiosos no se calman nunca, porque la realidad que los exaspera está ahî ${ }^{39}$.

Resulta de esta manera -escribe el autor vallisoletano en otra página posterior - cómo "parece que la sombra del compatriota, vivo o muerto, cercano o lejano, es [...] peligrosa ${ }^{40}$; ciertamente la realidad que exaspera lleva a que los envidiosos no se calmen nunca.

${ }^{36} \mathrm{Cfr}$. Historia de España Ramón Menéndez Pidal. vols. XXXIX/I y XXXIX/II, Madrid, Espasa Calpe. 1993 y 1994 (el responsable general de estos tomos ha sido el prof. don Pedro Laín Entralgo). Del mismo modo no coincidimos tampoco con la perspectiva temporal que asume José Carlos Mainer: La Edad de Plata (1902-1931), Barcelona, Eds. Asenet, 1975.

${ }^{37}$ Historiografía..., Universidad de Zaragoza, 1991

${ }^{38}$ Otra monografía - pero más atenta a la vida que a la obra - es la de Josep M. Muñoz i Lloret Jaume Vicens $i$ Vives, Una biografia intel-lectual, Barcelona, Edicions 62, 1997.

${ }^{39}$ Julián Marías, «Envidia retrospectiva», $A B C$ de 20 de Julio de 1995, p. 3.

${ }^{40}$ Julián Marías, «Hacer sombra», $A B C$ de 3 de Mayo de 1997, p. 3. 
Según decimos las historiografías particulares - y en concreto la de la filologíaprecisan asimismo de un tratamiento general que trace un mapa de situaciones de las mismas en el siglo XX; dentro de la centuria lo anterior a 1936 nos parece relativamente desatendido.

Las valoraciones que se hagan habrán de ser además cuidadosas, pues ya decimos que no faltan las perspectivas sesgadas: Marías ya sabemos que se ha visto obligado a advertirlo con reiteración.

\section{Generaciones intelectuales y de historiadores}

En el siglo XX se van sucediendo sucesivas generaciones de estudiosos algunos de cuyos nombres nos importan ahora. De la llamada generación del 98 ha de recordarse por lo menos a Rafael Altamira, Ramón Menéndez Pidal y Manuel Gómez Moreno; de la de 1914 a Ortega y Gasset (por sus contribuciones teóricas), a Américo Castro o a Ramón Carande, etc; coetáneos de los literatos del Veintisiete son Claudio Sánchez Albornoz, Melchor Fernández Almagro, Jesús Pabón, Luis García de Valdeavellano, ... La que podemos denominar "generación de 1936" (nacida entre 1906 y 1920) integra nombres especialmente relevantes en historiografía y en general en el cultivo de las ciencias humanas en España: los de José María Lacarra, Rafael Lapesa, Pedro Laín, Emilio Orozco Díaz, Antonio Domínguez Ortiz, Jaime Vicens, José Antonio Maravall, José Ferrater Mora, Julio Caro Baroja, Manuel Tuñón de Lara, Juan Reglá, José María Jover, etc., etc; sin duda resulta necesario que alguien escriba una monografía sobre ${ }^{*} \mathrm{La}$ generación intelectual de 1936.

Las generaciones posteriores son ya las de los autores absolutamente actuales: los que nacieron entre 1921 y 1935 (Miguel Artola, Luis Suárez Fernández, Nadal, Fontana, ...), entre 1936 y 1950 (Gabriel Tortella, Amando de Miguel, José Ángel García de Cortázar, Miguel Ángel Ladero, Antonio Elorza, etc.), y así sucesivamente.

Cuando hablamos de «generaciones» de historiadores no pretendemos en principio connotar nada respecto de ellos; a posteriori podrá establecerse en cada caso particular si en efecto un historiador (e. gr.) del 98 participa en algo de las actitudes de mentalidad que se dice caracterizan en general a los literatos del 98 , y así en el caso respectivo de cada una de las generaciones o grupos que hemos distinguido, que por lo menos sirven para situar cronológica e históricamente a los distintos autores.

\section{Altamira, Menéndez Pidal}

Rafael Altamira es un autor de mucho relieve, que ha tenido la fortuna de empezar a ser reconocido y valorado en estos últimos años; su proclama y su práctica en favor de la historia de la civilización ha encontrado además eco en la práctica actual del prof. José María Jover ${ }^{41}$. En cuanto a don Ramón Menéndez Pidal es un autor muy decisivo, y en él nos detendremos más.

\footnotetext{
${ }^{4 l}$ Cfr. para estos problemas el capítulo del propio Jover «Por una Historia de la civilización española», incluido en su bello libro La civilización española a mediados del siglo XIX, Madrid, Espasa Calpe, 1991 (pp. 305-387).
} 
Menéndez Pidal tuvo la fortuna de llegar a una edad avanzadísima en pleno vigor intelectual, y esto junto a una dedicación al estudio verdaderamente hercúlea y asombrosa, le hizo poder elaborar una obra en verdad ingente, tan amplia y densa como la de varias personas que hubiesen trabajado bastante (en el mundo de los profesores hay suficientes ejemplos de quienes están muy dedicados al estudio, aunque asimismo los hay - muchos menos - de quienes son perezosos o de quienes pretenden engañar citando sin haber leído, o firmando en cabeza lo que han escrito otros, ...).

En la obra de Menéndez Pidal concurren a la vez lo linguíístico, lo literario y lo histórico, pero no como componentes yuxtapuestos sino integrados, en un intento de registrar la coherencia mutua que puedan tener en cada situación. Reflejo de este propósito integrador es la obra antológica suya en dos volúmenes - creemos que poco conocida y manejada - España y su historia, que por supuesto no excusa la consulta de sus monografías extensas y anotadas ${ }^{42}$.

No escapa don Ramón (como no escapa persona alguna) a los condicionamientos de su tiempo y de la tradición intelectual en la que se ha formado, y en este sentido nosotros creemos - aunque no recordamos que se haya dicho hasta ahora - que el maestro gallego-asturiano se inserta en el romanticismo historiográfico, como asimismo estuvo impregnado en general de ese romanticismo historiográfico todo el «Centro de Estudios Históricos» de la Junta para Ampliación de Estudios. El romanticismo lleva seguramente a Menéndez Pidal a la temática medieval, a la exaltación de los héroes (el Cid), a la idea de los caracteres de los pueblos, ...

La manera de hacer Historia pidalina es a veces ideográfica (y esto se verá en títulos suyos: «Significación del reinado de Isabel la Católica, según sus coetáneos»; «Los Reyes Católicos según Maquiavelo y Castiglione», etc.); tal ideografía tiende a idealizar y a simplificar la realidad, pues lo histórico no es tanto lo conceptual e institucional como la realización o la transgresión de lo institucional, de lo legal, etc. La Historia no la constituyen principalmente los programas de gobierno, las disposiciones legales, las previsiones institucionales, sino la operatividad y la transgresión de esas realidades ideales. Jaime Vicens - aunque lo citamos ahora de memoria - ya disentía del sesgo ideográfico, filológico (y castellanista) de la historiografía pidalina.

\section{Sobre el siglo XI}

Dos obras magnas pidalinas anteriores a la guerra son Orígenes del español (1926) y La España del Cid (1929). Este segundo texto constituye un trabajo de sólida erudición que se halla dedicado además a uno de los momentos de mayor importancia en la trayectoria histórica española: la de los tiempos posteriores al año 1000; en este sentido decía así don Ramón al iniciar la obra:

Expone [...] este libro un cuadro general de España en el siglo XI, el siglo de nuestra historia más rico en momentos gravemente decisivos. En esa centuria la España de la época latino-árabe evolucionó hacia las condiciones posteriores de vida que constituyen la España moderna: dislocó por completo su centro de gravitación, de-

${ }^{42}$ Ramón Menéndez Pidal, España y su historia, Madrid, Eds. Minotauro, 1957, Tomos I y II. 
jando la órbita de un mundo histórico para entrar en la de otro mundo distinto. En el siglo XI además las fuerzas políticas que venían actuando en la Península desde la época antigua - Estado visigodo y disidencia vascona - pasaron a segundo término, adelantándose otras fuerzas nuevas a cuya cabeza se pone Castilla ${ }^{43}$.

España cabe decir que entra efectivamente en otro mundo histórico en la centuria del XI, y que entonces se dio un hondo cambio en la vida peninsular. Llevado de esta idea y de la de la frontera idiomática que sin duda ocurre en el mismo siglo -el propio don Ramón lo había mostrado en sus Orígenes del español-, creemos que fue como Américo Castro a su vez postulaba que la realidad histórica española empieza con posterioridad al año mil ${ }^{44}$.

Según queda apuntado el romanticismo historiográfico pidalino le inducía a destacar los caracteres heroicos, y en concreto el de Rodrigo Díaz, pero no ya su heroismo militar sino asimismo el moral; escribe de esta manera nuestro autor:

La vida del Cid nunca tuvo como principal ese aspecto guerrero que alguien puede creer único en ella [....]. El Cid ofreció siempre un mayor interés humano, palpitante en su grande obra contrariada y desagradecida.

Un héroe que lo es por su perdurable consagración a un propósito arduo; que rehace tenaz su obra, destruida varias veces, siempre coartado por la inexorable ira de su rey, siempre en lucha con el corpulento imperio almorávide y con los impalpables ejércitos de la envidia; Hércules histórico que supera la pertinaz enemiga de los dioses y la furia de los monstruos, será siempre un poderoso incitante para la juventud ${ }^{45}$.

Estamos ante un párrafo muy bello en el que el maestro subraya ya la heroicidad cidiana - heroicidad que se irá viendo a lo largo de su análisis - y en el que él mismo parece sumarse a esa moral de la consagración a un propósito arduo y de la lucha con los impalpables ejércitos de la envidia que descubre en Rodrigo: Menéndez Pidal advierte la grandeza de dedicar la vida a un propósito de envergadura, tal como él hacía en el estudio de la historia y la filología españolas.

Don Ramón analiza impecablemente desde el punto de vista erudito la España del siglo XI, y lo hace asimismo con un impulso historiográfico romántico que exalta la heroicidad militar y moral; al subrayar a Rodrigo en tanto héroe moral no se mueve sólo por una impregnación romántica, sino asimismo - creemos - en la traza de Giner de los Ríos y del espíritu institucionista.

El romanticismo historiográfico indujo asimismo la idea de los caracteres de los pueblos: Menéndez Pidal identifica así al Cid con el pueblo español, en cuanto muestra o ejemplo heroico de los caracteres generales de lo español:

${ }^{43}$ Citamos en este momento por R. Menéndez Pidal, La España del Cid, Madrid, Espasa-Calpe, 19697, p. VII.

44 «En el siglo del Cid - escribe por ejemplo también Pidal - , la vida española sufrió mudanzas más decisivas que nunca, lo mismo en sus fuerzas políticas que en sus relaciones mundiales, en sus aspiraciones, en el conjunto de su ideario» (Loc. cit., p. 78).

${ }^{45}$ Ibid., p. VIII. 
El Cid es el triunfo de la voluntad que supera lo insuperable, y en esto también es representativo de su nación más que cualquier figura eminente de otra clase. Entre los caracteres hispánicos más salientes se halla el predominio de la voluntad, el querer que arrolla las dificultades, que se sobrepone al pensamiento. Es la acción, descuidada de la perfección, lo que caracteriza lo mismo nuestra obra descubridora que nuestra literatura o nuestra industria ${ }^{46}$.

El genio de los pueblos interpreta el autor gallego-asturiano que se manifiesta de una determinada manera en el caso español, y así el Cid resulta además el héroe que representa en grado ejemplar tal genio colectivo propio.

Por igual La España del Cid esboza una idea de las primeras etapas en la trayectoria del concepto de España, y a este propósito mantiene Pidal:

El concepto de Hispania no fué una creación arbitraria de los romanos; antes los iberos habían iberizado a diversos otros pueblos de la Península, formando cierta unidad cultural o nacional hispánica. [...] Después el Estado único en que los visigodos reunieron la extrema provincia del Imperio de Roma, es la primera expresión política de la nueva idea de España. [... Con la invasión árabe ] el nombre mismo de Spania está entonces a punto de desnaturalizarse, pues tiende a designar especialmente el país islamizado por ser éste la mayor parte de la Península [...] Un sentimiento hispánico ligaba, ora ideal ora materialmente, a los diversos centros reconquistadores desde mucho antes que Castilla, una vez asumida la hegemonía en la Península, lograse implantar la unidad política ${ }^{47}$.

Don Ramón mantiene pues que el concepto político de España lo crean los visigodos, y que existió en efecto un concepto de España en la Edad Media; ambas tesis serían adoptadas e ilustradas muy ampliamente unos lustros más tarde por José Antonio Maravall ${ }^{48}$.

\section{Américo Castro}

A la llamada generación de 1914 pertenece Américo Castro, autor hoy bien conocido por las tesis intelectuales de su obra posterior a 1936, pero un tanto olvidado en lo que se refiere a lo que escribió antes de la guerra. El Américo de la juventud y de la primera madurez fue oficialmente catedrático de «Historia de la Lengua Española», aunque en realidad a esta materia que le estaba asignada académicamente sólo se dedicó muy en parte: él era un estudioso sobre todo de la literatura y la cultura, un poco al modo de Menéndez Pelayo; en esta traza su libro de mayor relieve fue -como bien se sabe-El pensamiento de Cervantes.

46 Ibid., p. 656.

${ }^{47}$ Ibid., pp. 65-66.

${ }^{48}$ Para otra visión del siglo XI castellano cfr. Carlos Estepa, El reinado de Alfonso VI, Madrid, Spainfo Ings., 1985, y varios tratadistas más. 
Lo que viene a mostrar don Américo con el caso de Cervantes es que en la España del siglo XVI «hubo alta cultura del espíritu» ${ }^{49}$, es decir y más en particular, que «España participó de las corrientes renacentistas» ${ }^{50}$; Cervantes se nos presenta así como un renacentista:

Las bases de sus caracteres literarios son quintaesencia del naturalismo y el estoicismo de su siglo. La psicología de sus personajes -empirismo, relativismo y «engaño a los ojos» - nos lleva a los estados de espíritu más exquisitos dentro del Renacimiento precartesiano. La moral naturalista y estoica da en él frutos originales. La religiosidad es igualmente la que hallamos en otros grandes genios de su época. [...] Cervantes se nos muestra plenamente como una de las más espléndidas floraciones del humanismo renacentista ${ }^{51}$.

Nuestro autor hace ahora en la presente monografía cervantina Historia de la cultura e Historia literaria; al pasar de los años y tras la guerra, llegará a la práctica de una verdadera Historia de las mentalidades. Aunque con posturas intelectuales distintas, don Américo trabaja al igual que Menéndez Pelayo en la Historia de la cultura española: se halla profesionalmente más en esta traza que en la muy filológica de Menéndez Pidal.

${ }^{49}$ El pensamiento de Cervantes por Américo Castro, Madrid, Centro de Estudios Históricos-Imprenta de la Librería y Casa Editorial Hernando, 1925, p. 384.

${ }^{50}$ Ibid., p. 386.

${ }^{51}$ Ibid., pp. 387-388. 